\title{
Stereochemical Characterization of Poly(pentyl acrylate) by One and Two Dimensional NMR Spectroscopy
}

\author{
Ajaib Singh BraR ${ }^{\dagger}$ and Kaushik DutTa \\ Department of Chemistry, Indian Institute of Technology, \\ Hauz Khas, New Delhi 110 016, India
}

(Received August 28, 1997)

\begin{abstract}
The stereochemical structures of poly(pentyl acrylate) (PPA) prepared by solution polymerization is studied by the combination of one and two dimensional NMR spectroscopy. The $\mathrm{OCH}_{2}$, methine, methylene, and the carbonyl carbon resonances are assigned to triad, tetrad and pentad sequences respectively. The polymerization mechanism was studied using the carbonyl and $\mathrm{OCH}_{2}$ resonances. It was found that homopolymerization followed Bernoullian statistics. The various configurational assignments in the aliphatic region were done with the help of inverse HETCOR, inverse HETCOR-TOCSY, homonuclear DQFCOSY experiments.

KEY WORDS Poly(pentyl acrylate) / 1D and 2D Nuclear Magnetic Resonance Spectroscopy / Stereochemical / Microstructure /
\end{abstract}

Homo and copolyacrylates are of great interest in many industrial applications because of their wide range of physical and chemical properties that can be covered by an appropriate choice of side groups and copolymer system. Poly(pentyl acrylate) (PPA) is used as a viscosity index improver because of large pendant group. The physical and chemical properties of these polymers are greatly influenced by the microstructure, which involves the monomer distribution in the polymer chain and stereochemical arrangement of various groups. Thus the determination of configurational sequence distribution appears to be important. ${ }^{1}$ The knowledge of the microstructure is essential to study the polymerization mechanism. ${ }^{2}$ NMR spectroscopy is probably the most efficient technique for characterization of the stereochemical structure of polymers. ${ }^{3,4}$ Many workers ${ }^{5-9}$ have reported the stereochemical structure of polyacrylates by conventional one dimensional NMR spectroscopy. The contribution of two dimensional nuclear magnetic resonance spectroscopy (2D NMR) to the study of homopolymer microstructure has been universally recognized. ${ }^{10}$ Recently, the microstructure of the polyacrylates were studied by the application of inverse HETCOR (heteronuclear correlation) and DQFCOSY NMR spectroscopies. ${ }^{11-13}$

In this manuscript, we report the microstructure of PPA and the polymerization mechanism. The various carbon resonances are assigned to triad, tetrad and pentad configurational sequences with the help of two dimensional homonuclear (DQFCOSY) and heteronuclear (inverse HETCOR) correlation NMR spectroscopy. 2D ${ }^{1} \mathrm{H}-{ }^{13} \mathrm{C}$ heteronuclear correlation was used to assign the proton NMR spectra of the homopolymers. The geminal and the vicinal couplings possible in the various configurational sequences in the homopolymer were studied by $2 \mathrm{D}{ }^{1} \mathrm{H}-{ }^{1} \mathrm{H}$ DQFCOSY NMR spectroscopy.

\footnotetext{
${ }^{\dagger}$ To whom all correspondence should be addressed.
}

\section{EXPERIMENTAL}

Pentyl acrylate was synthesized by esterification of pentanol with acrylic acid using the Dean and Stark apparatus. Benzene was used as azeotropic agent to remove the water from the reaction mixture. The monomer was vacuum distilled and stored below $5^{\circ} \mathrm{C}$. The PPA was prepared by solution polymerization using benzoyl peroxide as intiator in DMF at $65^{\circ} \mathrm{C}$. The homopolymer was precipitated in methanol and was reprecipitated using the $\mathrm{CHCl}_{3} / \mathrm{CH}_{3} \mathrm{OH}$ solvent system.

NMR experiments were performed in $\mathrm{CDCl}_{3}$ on Bruker $300 \mathrm{MHz}$ DPX spectrometer at a frequency of $300.13 \mathrm{MHz}$ and $75.5 \mathrm{MHz}$ for ${ }^{1} \mathrm{H}$ and ${ }^{13} \mathrm{C}\left\{{ }^{1} \mathrm{H}\right\}$ NMR spectrum, respectively. DEPT measurements were carried in $\mathrm{CDCl}_{3}$ using the standard pulse sequence with a $J$ modulation time of $3.7 \mathrm{~ms}\left(J_{\mathrm{CH}}=135 \mathrm{~Hz}\right)$ with $2 \mathrm{~s}$ delay time. Two dimensional proton detected ${ }^{1} \mathrm{H}-{ }^{13} \mathrm{C}$ heteronuclear chemical shift correlation and inverse HETCOR relay spectra were recorded in $\mathrm{CDCl}_{3}$ using the standard pulse sequence. ${ }^{14,15}$ A total of 32 scans were accumulated with a relaxation delay of $2 \mathrm{~s}$ for each of the $512 \mathrm{t}_{1}$ experiments. The mixing time for the inverse HETCOR relay experiment was $6.4 \mathrm{~ms}$. The DQFCOSY experiment, with 32 scans being collected for each $t_{1}$ value was carried out in $\mathrm{CDCl}_{3}$. A total of 512 spectra each containing the $1 \mathrm{~K}$ data points were accumulated. The details of the Lorentzian shaped curve fitting have been described in our earlier publication. ${ }^{16}$ All regressions converged to $\chi^{2}<1$.

\section{RESULTS AND DISCUSSION}

The ${ }^{13} \mathrm{C}\left\{{ }^{1} \mathrm{H}\right\}$ NMR spectrum of the PPA in $\mathrm{CDCl}_{3}$ is shown in Figure 1. The various carbon resonance signal were assigned with the help of DEPT-135 experiment. Figure 2 shows the DEPT-135 NMR spectrum of the homopolymer in which the methylene carbon resonances have negative phase and the methine and the methyl carbon resonances show positive signals. The alkyl side chain methylene carbons show signal around $\delta 63.68$, 

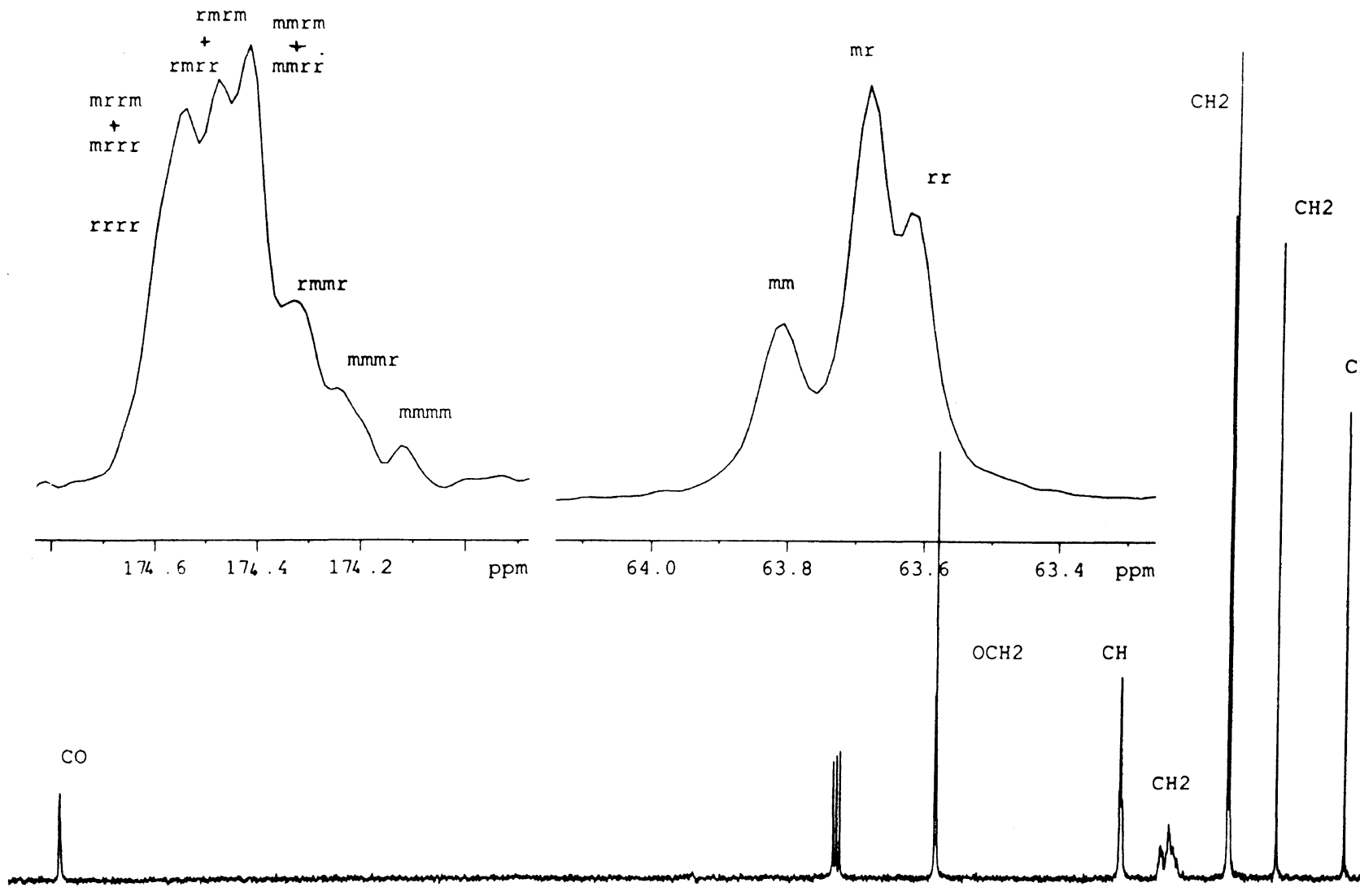

$\mathrm{CH} 2$

$\begin{array}{llllllll}170 & 160 & 150 & 140 & 130 & 120 & 110 & 100\end{array}$

90

80

pm

Figure 1. The $75.5 \mathrm{MHz}{ }^{13} \mathrm{C}\left\{{ }^{1} \mathrm{H}\right\} \mathrm{NMR}$ spectrum of PPA in $\mathrm{CDCl}_{3}$, along with the expanded carbonyl and $-\mathrm{OCH} \mathrm{H}_{2}$ carbon resonances.

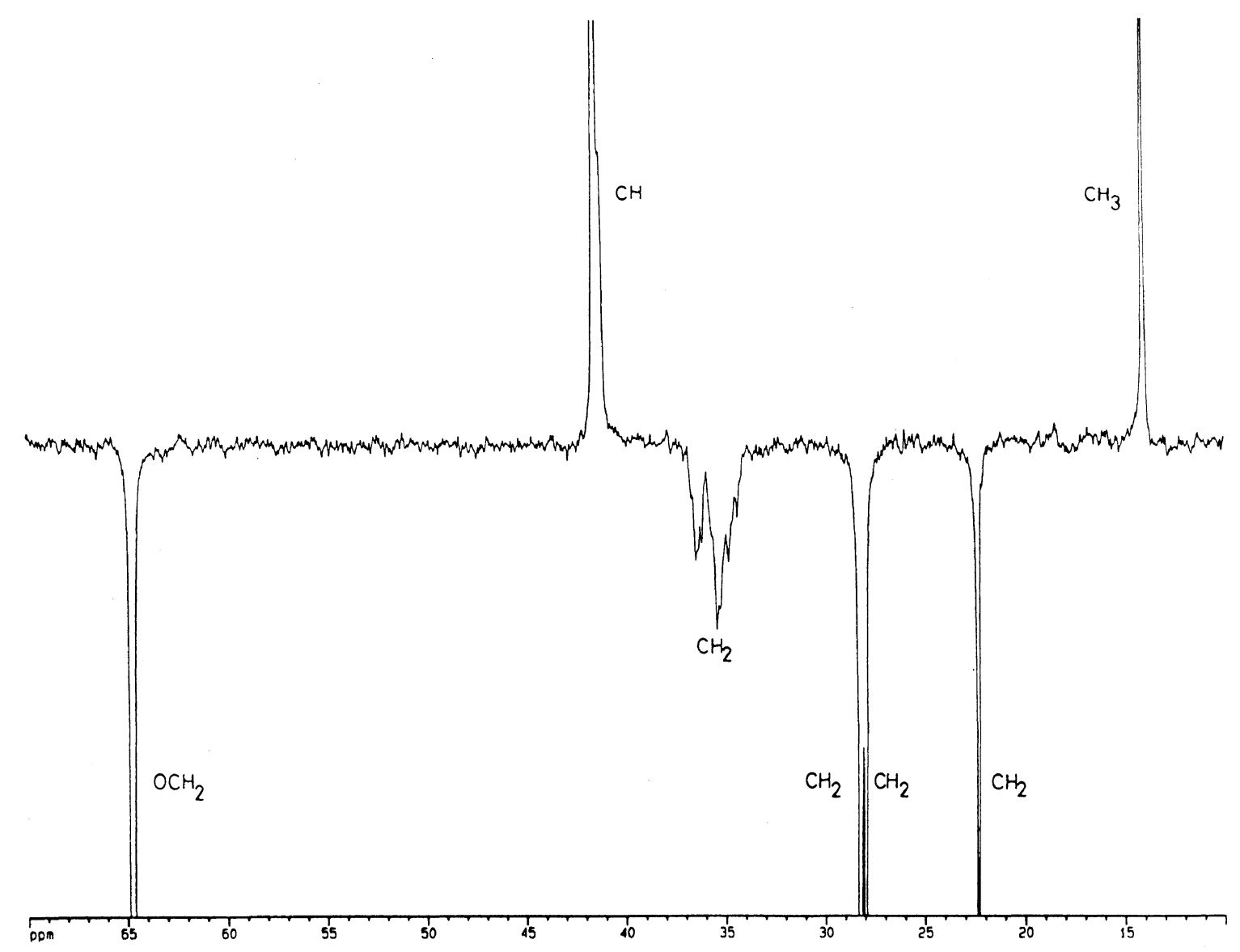

Figure 2. The DEPT-135 NMR spectrum of PPA in $\mathrm{CDCl}_{3}$. 
$\delta 28.24, \delta 27.94$, and $\delta 22.46 \mathrm{ppm}$ which are assigned to $-\mathrm{OCH}_{2},{ }^{2} \mathrm{CH}_{2},{ }^{3} \mathrm{CH}_{2}$, and ${ }^{4} \mathrm{CH}_{2}$. The side chain methyl carbon resonances around $\delta 13.93 \mathrm{ppm}$. The $\beta$-methylene and the methine carbon signals shows multiplets around $\delta 33.0-36.0$ and $\delta 40.0-40.75 \mathrm{ppm}$, respectively. The $\mathrm{OCH}_{2}$ carbon signals show three multiplet around $\delta 63.4-63.65, \delta 63.65-63.76$, and $\delta 63.76-64.0$ ppm, which are assigned to $r r, r m / m r$, and $m m$ from high to low field. The triad concentration were calculated from the area under these signals. From these triad fractions, using the Bernoullian statistics, ${ }^{3}$ the probability of meso addition to the growing polymer chain $(P m)$ was calculated. The average value of $P m$ from the triad fractions is 0.425 . Using the triad concentration data, one can test whether the propagation reaction obeys Bernoullian statistics. The probability that the monomer unit added to a growing polymer chain terminated by a racemic diad will generate a meso diad $\left(P_{r / m}\right)$ is given by the relation ${ }^{3}$

$$
P_{r / m}=\frac{m r}{2 r r+m r}
$$

and similarly for $P_{m / r}$

$$
P_{m / r}=\frac{m r}{2 m m+m r}
$$

when $P_{r / m}+P_{m / r}=1$, then chain propagation obeys Bernoullian statistics. For PPA, the sum of the $P_{r / m}$ and $P_{m / r}$ equals 0.95 , which approximate to 1 within ex-
Table I. The experimentally and statistically determined

\begin{tabular}{|c|c|c|c|c|c|}
\hline \multirow{2}{*}{ Triads } & \multicolumn{5}{|c|}{ Triad fractions } \\
\hline & Theoretical $^{\mathrm{a}}$ & $-\mathrm{OCH}_{2}{ }^{\mathrm{b}}$ & Carbonyl $^{\text {b }}$ & Methine $^{b}$ & $\begin{array}{l}\text { Meth- } \\
\text { ylene }^{b}\end{array}$ \\
\hline$m m$ & 0.18 & 0.21 & 0.21 & 0.17 & \\
\hline$m r(r m)$ & 0.49 & 0.47 & 0.47 & $0.83^{\mathrm{c}}$ & \\
\hline$r r$ & 0.33 & 0.32 & 0.32 & & \\
\hline $\mathrm{mmm}$ & 0.08 & & & & 0.12 \\
\hline $\mathrm{rmm}$ & 0.21 & & & & 0.20 \\
\hline$r m r$ & 0.14 & & & & 0.08 \\
\hline$m r m$ & 0.10 & & & & 0.13 \\
\hline $\mathrm{rrm}$ & 0.28 & & & & 0.27 \\
\hline$r r r$ & 0.19 & & & & 0.19 \\
\hline $\mathrm{mmmm}$ & 0.03 & & 0.02 & & \\
\hline$m m m r$ & 0.09 & & 0.10 & & \\
\hline$r m m r$ & 0.06 & & 0.09 & & \\
\hline \multicolumn{6}{|l|}{ mmrm } \\
\hline+ & 0.21 & & 019 & & \\
\hline \multicolumn{6}{|l|}{$m m r r$} \\
\hline $\mathrm{rmrm}$ & 0.12 & & 0.10 & & \\
\hline$r m r r$ & 0.16 & & 0.18 & & \\
\hline \multicolumn{6}{|l|}{ mrrm } \\
\hline+ & 0.22 & & 0.19 & & \\
\hline \multicolumn{6}{|l|}{$m r r r$} \\
\hline$r r r r$ & 0.11 & & 0.13 & & \\
\hline
\end{tabular}
triad fractions of various carbon resonances

${ }^{a}$ Calculated from Bernoullian Statistics using $P m=0.425$. ${ }^{\mathrm{b}}$ Determined from ${ }^{13} \mathrm{C}\left\{{ }^{1} \mathrm{H}\right\}$ NMR spectrum. ${ }^{\mathrm{c}}$ The triad concentration of 0.83 is inclusive of $m r(r m)+r r$.

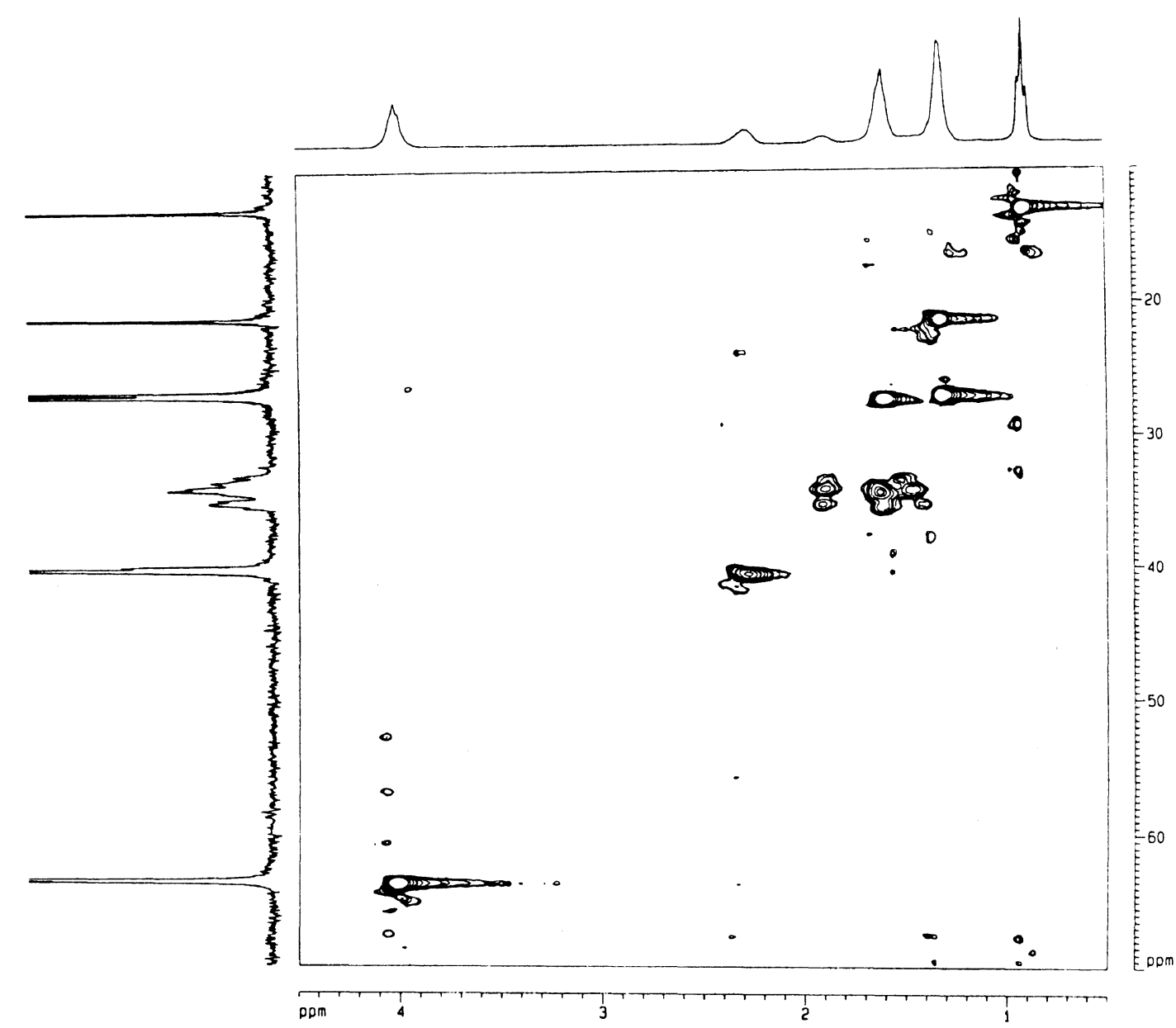

Figure 3. The $300 \mathrm{MHz}{ }^{1} \mathrm{H}^{13} \mathrm{C}$ proton detected heteronuclear shift correlation spectrum of PPA. 


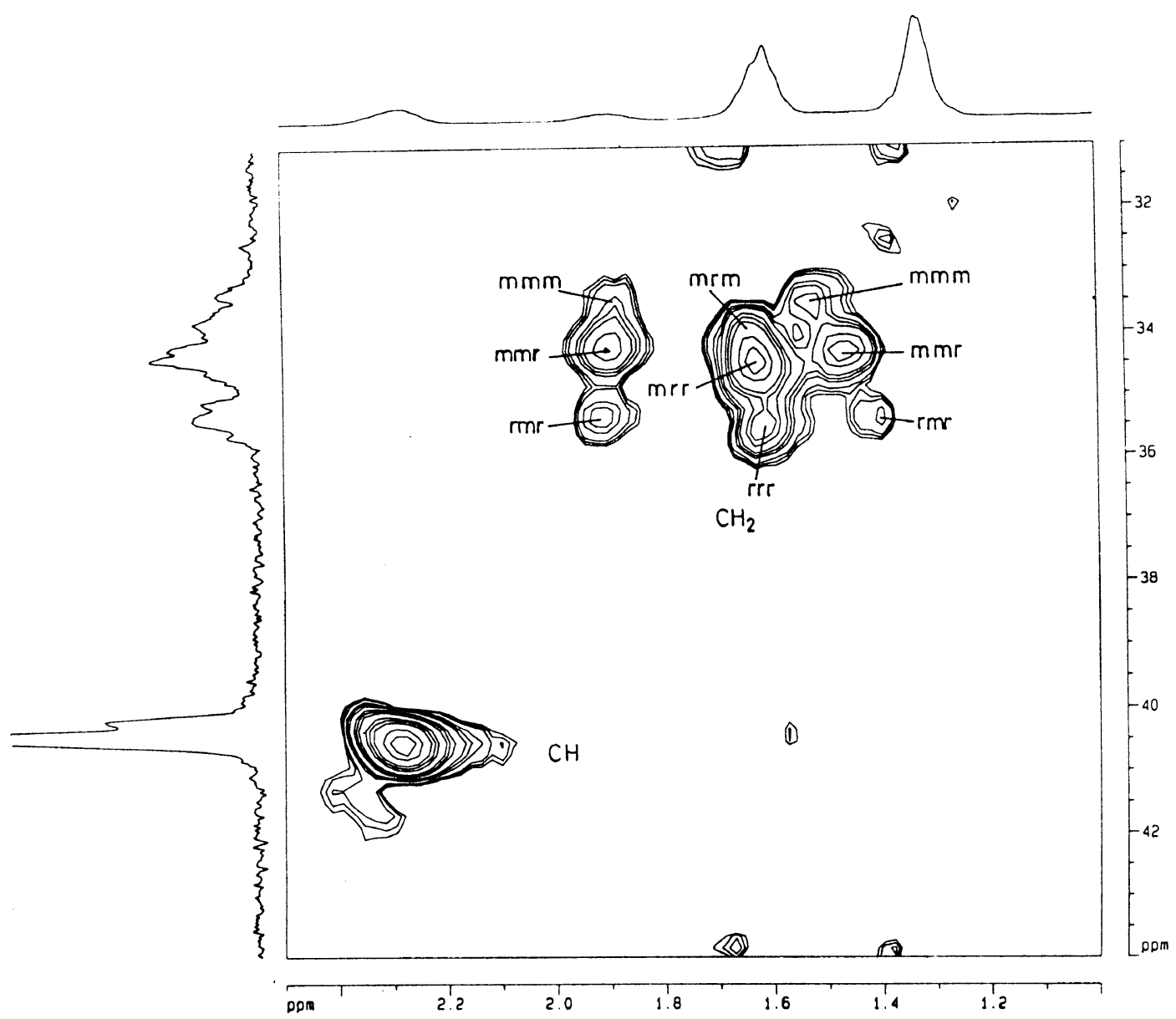

Figure 4. The inverse HETCOR spectrum of PPA, showing the methine and the methylene correlation cross peaks.

perimental error, thus the polymerization obeys Bernoullian statistics. This $P m$ value was used to calculate the triad, tetrad and pentad sequences concentration in the homopolymer.

The signals around $\delta 174.0-174.7 \mathrm{ppm}$ are assigned to the carbonyl carbon resonances. The signals around $\delta 174.0-174.35, \delta 174.35-174.52$, and $\delta 174.52-174.7$ ppm are assigned to $m m, m r / r m$, and $r r$ triads. The further splitting within these triad fractions can be assigned to pentad sequences (Figure 1). Therefore the signals at $\delta 174.11, \delta 174.25$, and $\delta 174.3 \mathrm{ppm}$ are assigned to $\mathrm{mmmm}, \mathrm{mmmr}(\mathrm{rmmm})$, and $\mathrm{mmrm}$ pentad sequences. In the $m r$ triad fraction region the signals at $\delta 174.41$, $\delta 174.6$, and $\delta 174.5 \mathrm{ppm}$ are assigned to $m m r m+m m r r$, rmrm, and rmrr pentads. The rrrr and $m r r m+m r r r$ pentads are assigned at $\delta 174.57$ and $\delta 174.53 \mathrm{ppm}$, respectively. These assignments are based on the assignments done by Bovey et $a .^{3}$ for poly(methyl methacrylate) (PMMA). These assignments are also confirmed by calculating the area under these signals and comparing them with those calculated using the Bernoullian statistics $(P m=0.425)$. There was good agreement between the experimentally and statistically determined triad and pentad fractions (Table I).

The methine carbon signal also shows triad configurational sensitivity. The $\mathrm{mm}$ triad fraction which appears at higher field $(\delta 40.18 \mathrm{ppm})$ whereas the $m r$ and $r r$ triad fractions are not distinguishable and appears at $\delta 40.34 \mathrm{ppm}$. The $\beta$-methylene carbon resonance signal shows tetrad sensitivity which were assigned with the

Polym. J., Vol. 30, No. 4, 1998 help of the 2D inverse-HETCOR as demonstrated by Suchoparek et al. ${ }^{11}$ Figure 3 shows the inverse-HETCOR NMR spectrum of PPA. The $m$ centered tetrads ( $m m m$, $m m r$, and $r m r$ ) have non-equivalent methylene protons, thus will show two crosspeaks in the F2 domain of the 2D spectrum (Figure 4) whereas the $r$ centered tetrads ( $\mathrm{mrm}, \mathrm{mrr}$, and $r r r$ ) will show one correlation crosspeak. Roman et al. ${ }^{1}$ showed that the chemical shift of the $m$ centered tetrads increases in the order $m m m, m m r$, and $r m r$. Thus the correlation cross peaks at $\delta 33.36 / 1.51(\delta 33.36 / 1.88), \delta 34 / 19 / 1.46$ $(\delta 34.19 / 1.89)$, and $\delta 35.23 / 1.41(\delta 35.23 / 1.91) \mathrm{ppm}$ are assigned to $m m m, m m r$, and $r m r$ tetrads. The $r$ centered tetrads are assigned at $\delta 35.39 / 1.61(\mathrm{rrr}), \delta 34.32 / 1.62$ $(\mathrm{mrr})$, and $\delta 33.74 / 1.64(\mathrm{mrm}) \mathrm{ppm}$. The area under these tetrad fraction were calculated from the methylene region of the ${ }^{13} \mathrm{C}\left\{{ }^{1} \mathrm{H}\right\}$ NMR spectrum. The expanded methylene and methine carbon resonances are shown in Figure 5. These tetrad fraction were then compared with those found out using the Bernoullian statistical model (Table I). There is good agreement between the experimentally determined and statistically determined tetrad fractions, thus confirming the assignments.

Figure 6 shows the ${ }^{1} \mathrm{H}_{-13} \mathrm{C}$ heteronuclear relay (through $\mathrm{HOHAHA}$ ) spectrum of PPA in $\mathrm{CDCl}_{3}$. In the spectrum apart from the correlation crosspeaks, relayed coupling by magnetization transfer through spin system are also observed. The long range relay coupling will be seen at longer mixing time whereas the direct couplings will be seen at shorter mixing time. The directly 

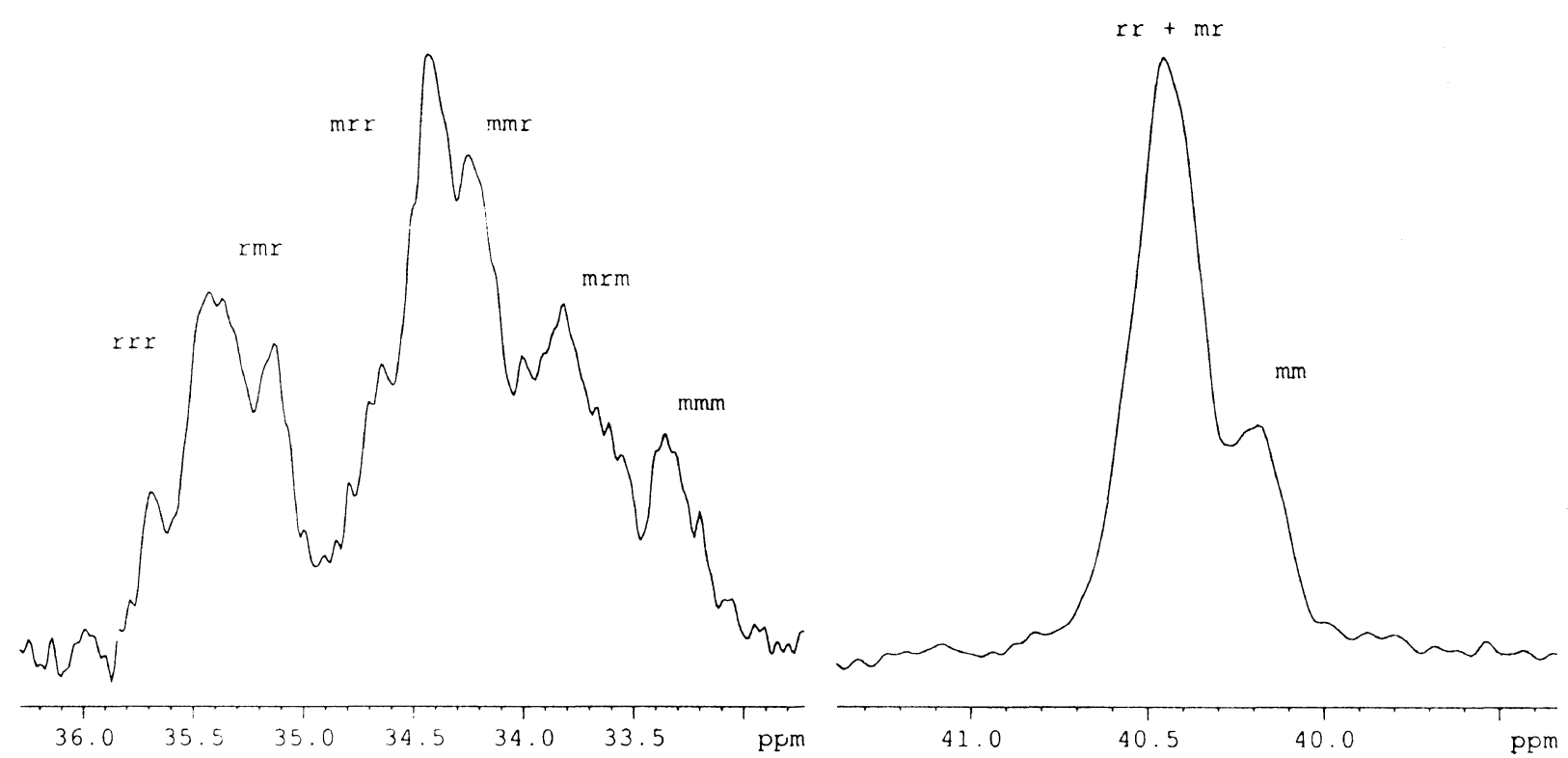

Figure 5. The expanded ${ }^{13} \mathrm{C}\left\{{ }^{1} \mathrm{H}\right\}$ NMR spectrum of PPA showing the methine and the $\beta$-methylene carbon resonances.
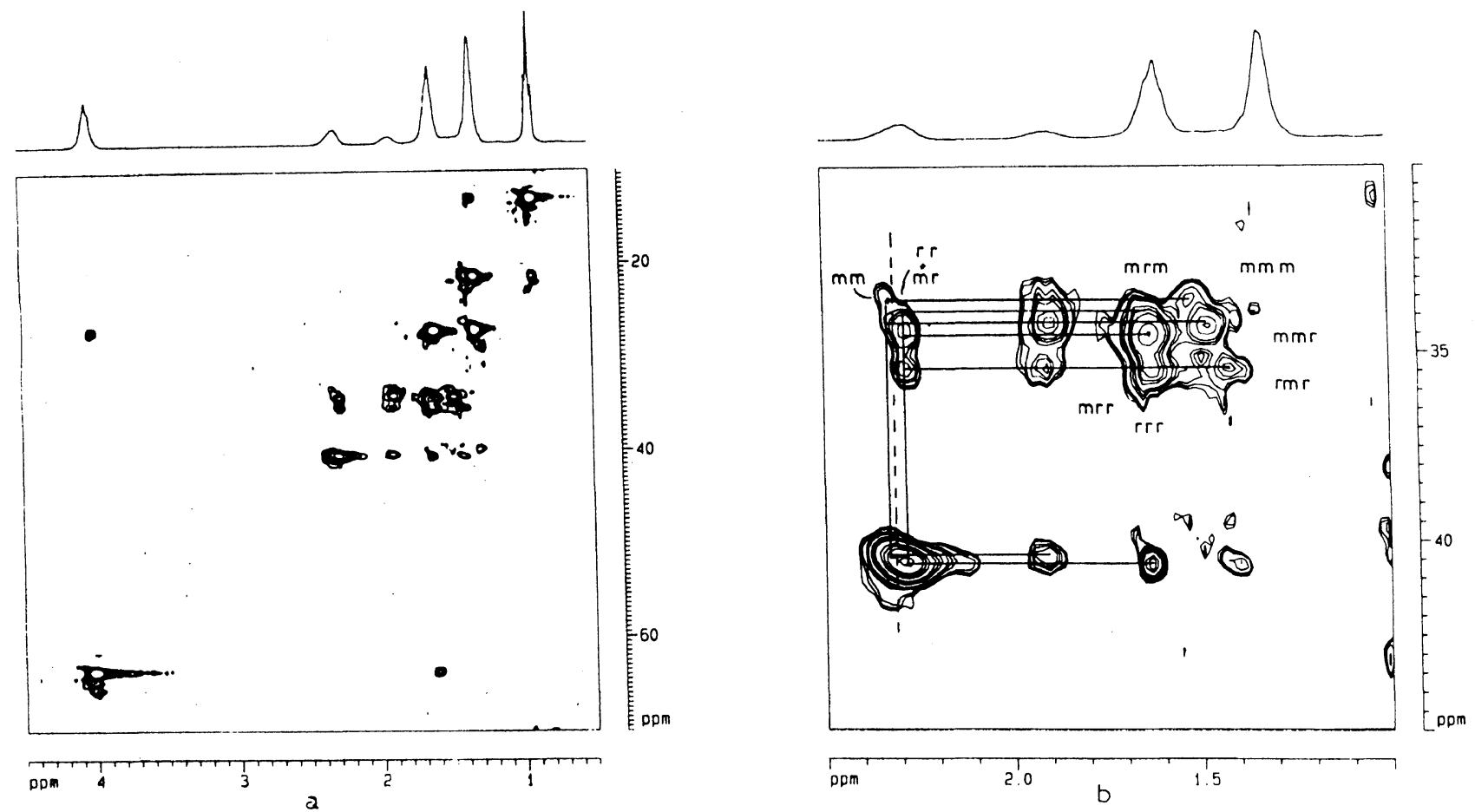

Figure 6. The inverse HETCOR relay (through spin lock) correlation spectrum, (a) the complete spectrum, (b) the expanded portion showing the methine and the methylene regions, of PPA.

correlating $\beta$-methylene crosspeaks are marked on the basis of the above assignment. The corresponding relay peaks, arising from the magnetization transfer from $\mathrm{CH}_{2}$ protons to the neighbouring $\mathrm{CH}$ proton confirms the above assignments. The methylene protons in $r r r, m r m$, $\mathrm{rmr}$, and $\mathrm{mmm}$ tetrads will give relay peaks to $\mathrm{rr}, \mathrm{mr}$, and $m m$ methine protons. The $m r r$ and $m m r$ methylene proton will show relay peaks with $m r, r r$ and $m m, m r$ methine protons.

From the heteronuclear correlation spectroscopy the ${ }^{1} \mathrm{H}$ NMR spectrum is completely assigned. Figure 7 shows the ${ }^{1} \mathrm{H}$ NMR spectrum of PPA in $\mathrm{CDCl}_{3}$. The methine protons at $\delta 2.27$ and $\delta 2.32 \mathrm{ppm}$ are assigned to $m m$ and $m r+r r$ triad fractions. The geminal coupling of the non equivalent methylene proton in the $m$ centered tetrads are clearly seen in the COSY spectrum (Figure 8). The cross peaks at $\delta 1.1 .91 / 1.41,1.89 / 1.46$, and $1.88 / 1.51 \mathrm{ppm}$ are due to the geminal couplings of the methylene protons in $r m r, m m r$, and $\mathrm{mmm}$ tetrads. The coupling between the methine proton with the two different methylene protons in the $\mathrm{mm}$ triad fraction are at $\delta 2.34 / 1.88$ and $\delta 2.34 / 1.49 \mathrm{ppm}$. Similarly, the $\mathrm{CH} / \mathrm{CH}_{2}$ couplings in the $m r$ triad fraction are at $\delta 2.29 / 1.91$ and $\delta 2.29 / 1.43 \mathrm{ppm}$. Due to the cancellation of the crosspeaks in the DQFCOSY spectrum, these cross peaks are clearly seen in the low mixing 

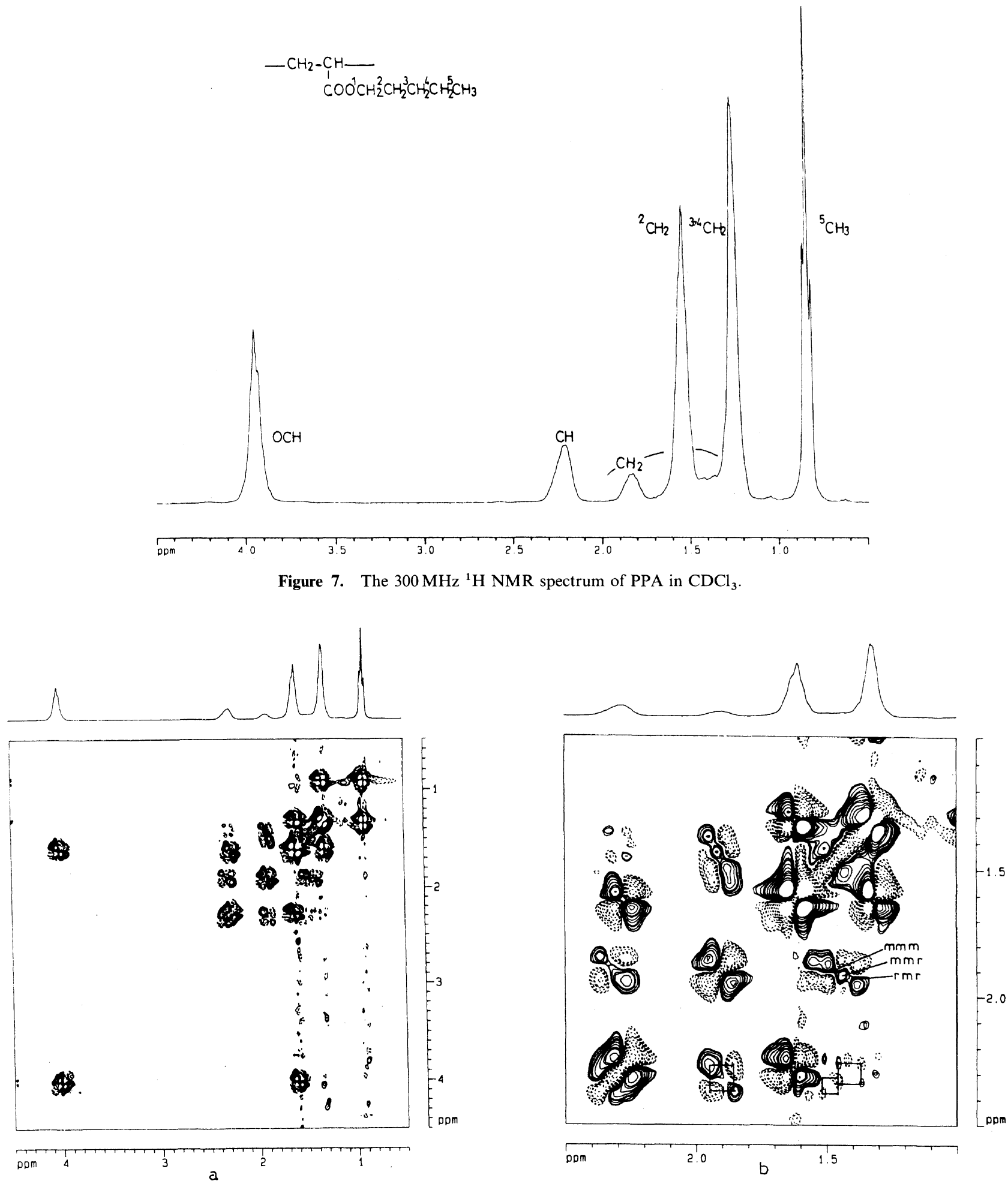

Figure 8. The homonuclear 2D DQFCOSY spectrum of PPA in $\mathrm{CDCl}_{3}$, (a) complete spectrum, (b) expanded region showing the methine/methylene couplings.

time TOCSY $(4 \mathrm{~ms})$ spectrum.

\section{CONCLUSIONS}

The microstructure of the PPA was determined with the help of ${ }^{13} \mathrm{C}\left\{{ }^{1} \mathrm{H}\right\}$ NMR spectroscopy. The polymerization mechanism was found to obey Bernoullian statistics. There was good agreement between the experimentally and statistically determined triad, tetrad, and pentad fractions. The various configurational assignments of the carbon and proton resonances were done with the help of both homonuclear (DQFCOSY) and heteronuclear (inverse HETCOR and inverse HETCOR-relay) correlation NMR spectroscopy.

Acknowledgments. The authors are thankful to the Indian Institute of Technology, Delhi for providing the NMR facility and financial support. 


\section{REFERENCES}

1. A. Bulai, M. L. Jimeno, and J. S. Roman, Macromolecules, 28, 7363 (1995).

2. J. C. Ronda, A. Serra, A. Montecon, and V. Cadiz, Polymer, 36, 471 (1995).

3. F. V. Bovey, "High Resolution NMR of Macromolecules," Academic Press, New York, N.Y., 1972.

4. J. C. Randal, "Polymer Sequence Determination (Carbon-13 NNR Methods)," Academic Press, New York, N.Y., 1977.

5. K. Matsuzaki, T. Uryu, A. Ishida, T. Ohki, and M. Takeuchi, $J$. Polym. Sci., A-1, 5, 2167 (1967).

6. T. Yoshino, M. Shinomiya, and J. Komiyama, J. Am. Chem. Soc., 87, 387 (1965).
7. K. Matsuzaki, K. T. Kanai, T. Kawamura, S. Matsumoto, and T. Uryu, J. Polym. Sci., Chem. Ed., 11, 961 (1973).

8. A. Spyros and P. Dais, Macromolecules, 25, 1062 (1992).

9. I. Goni, M. Gurrachaga, M. Valero, and G. M. Guzman, Polymer, 34, 1780 (1993).

10. L. Dong, D. J. T. Hill, J. H. O'Donnell, and A. K. Whittakar, Macromolecules, 27, 1830 (1994).

11. M. Suchoparek and J. Spevacek, Macromolecules, 26, 102 (1993).

12. M. Suchoparek, J. Spevacek, and B. Masar, Polymer, 35, 3389 (1994).

13. A. S. Brar, M. Thiyagarajan, and K. Dutta, Polymer, in press.

14. A. Bax and S. Subramaniam, J. Magn. Reson., 67, 565 (1986).

15. L. Lerner and A. Bax, J. Magn. Reson, 69, 375 (1986)

16. A. S. Brar, K. Dutta, and G. S. Kapur, Macromolecules, 28, 8735 (1995). 